\title{
Influence of fruit logistics on fresh-cut pineapple (Ananas comosus [L.] Merr.) volatiles assessed by HS-SPME-GC-MS analysis
}

\author{
Christof B. Steingass ${ }^{1,2}$ (D) Jennifer Dickreuter ${ }^{2} \cdot$ Sabine Kuebler $^{2,3} \cdot$ Ralf M. Schweiggert $^{1} \cdot$ Reinhold Carle $^{2,4}$
}

Received: 29 September 2020 / Revised: 12 March 2021 / Accepted: 14 March 2021 / Published online: 31 March 2021

(c) The Author(s) 2021

\begin{abstract}
Green-ripe pineapples are shipped overseas by sea freight, while those picked at full maturity need to be transported by airfreight over the same large distance. In this study, fresh-cut pineapple cubes were assessed two, five, and eight days after processing from green-ripe pineapples after mimicked sea freigh (SF) and fully ripe air-freighted (AF) pineapples. The sea-freighted samples displayed elevated titratable acidity (TA), thus resulting in smaller ratios of total soluble solids and TA compared to the AF pineapples. Differences in the carotenoid levels of the two fresh-cut categories were found to be insignificant. By contrast, hierarchical cluster analysis (HCA) and principal component analysis (PCA) calculated on the basis of the volatiles analysed by headspace solid-phase microextraction-gas chromatography-mass spectrometry (HSSPME-GC-MS) permitted to distinguish all six individual sample types and to segregate them into two major clusters (SF and AF). The effect of storage on the volatiles was further evaluated by partial least squares (PLS) regression. Substantial chemical markers to differentiate the individual samples and to describe the effect of storage were deduced from the PCA and PLS regression, respectively. In general, fresh-cut products obtained from fully ripe AF fruit displayed higher concentrations of volatiles, in particular, increased concentrations of diverse methyl esters. With progressing storage duration, the concentrations of ethanol and diverse ethyl esters increased. Moreover, products from AF pineapples displayed lower microbial counts compared to those from SF fruit.
\end{abstract}

Keywords Volatiles $\cdot$ Profiling analysis $\cdot$ Supply chain $\cdot$ Fruit logistics

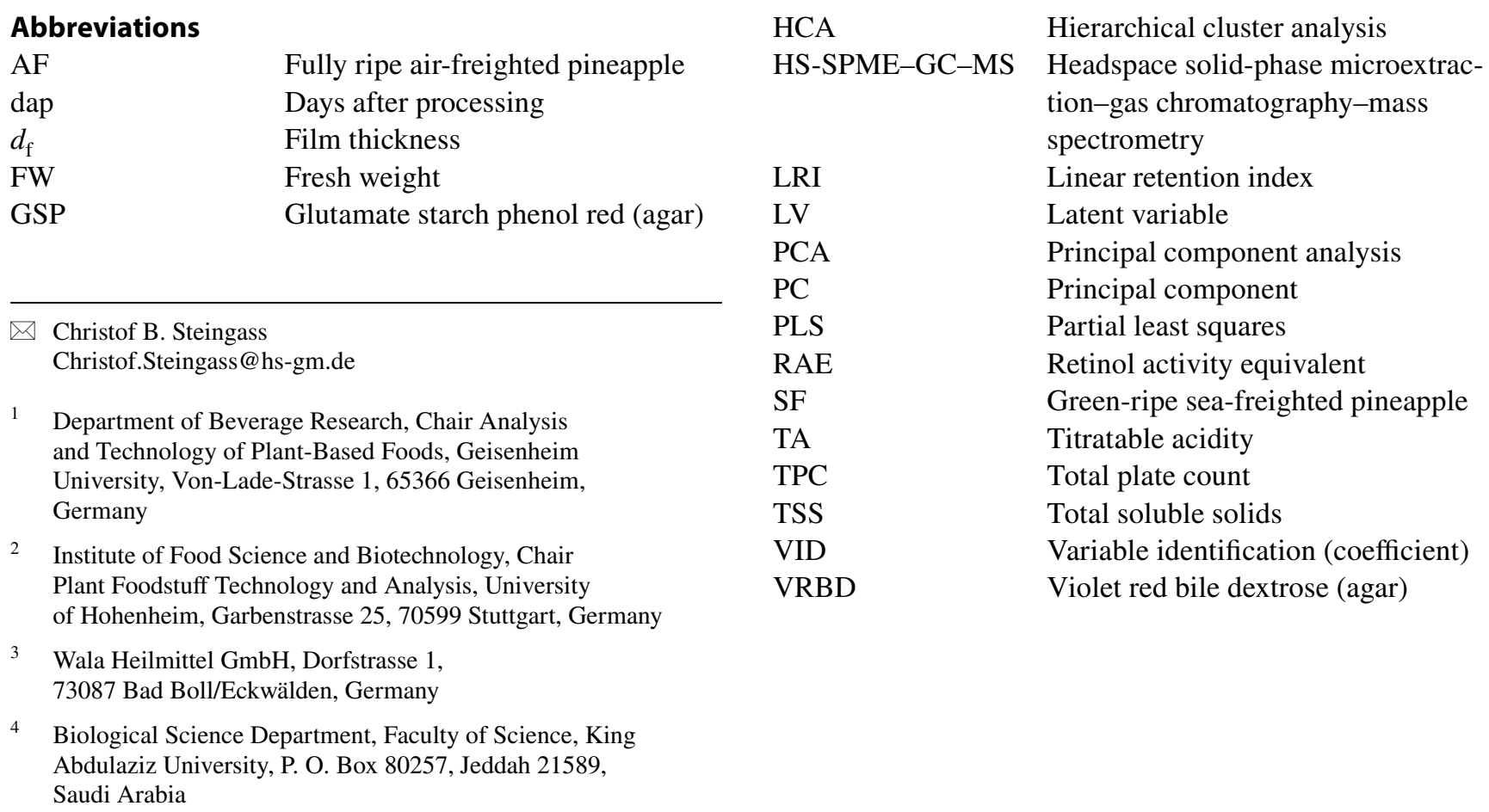




\section{Introduction}

Owing to their exotic flavour, consumers in Europe and North America highly appreciate tropical fruits and products derived thereof. In the pineapple market, fresh fruit and fresh-cut products represent still growing sectors. Two principal logistic chains have been established for supplying the European market with fresh-cut pineapples. The first is based on harvesting fully ripe fruit, which are processed in close proximity to their production sites and then immediately exported by rapid airfreight [1]. For instance, the German and Britain markets are majorly supplied with this premium niche product by two major companies airfreighting fresh-cut fruits from Ghana to Europe [2]. The second chain is based on harvesting early green-ripe pineapples having an extended shelf life under chilled conditions, which permits their transport for multiple weeks by cargo ships. The major proportion of these sea-freighted pineapples is sold on the fresh fruit market. With regard to fresh-cut product manufacture, processing facilities located, e.g., in Europe and North America mostly rely on such sea-freighted fruit.

Pineapple volatiles have been intensely studied during the past decades [3]. In a previous study, fully ripe air-freighted pineapples and three post-harvest stages of green-ripe, sea-freighted fruit were assessed by solidphase microextraction and gas chromatography-mass spectrometry (HS-SPME-GC-MS), revealing clear-cut differences in their volatiles [4]. In addition, the odour, taste, and overall preference of air-freighted pineapples were significantly better rated by a consumer panel compared to sea-freighted fruit assessed at two post-harvest stages [5]. By analogy to fresh fruit, also quality of freshcut products obtained from fully ripe and green-ripe seafreighted pineapples may differ.

The volatiles of fresh-cut pineapples were investigated by Spanier et al. [6] during a 10-day storage period. Lamikanra [7] reported the involvement of esterases in the development of staleness in sliced pineapples. The effects of ultraviolet (UV) light irradiation [8] and modified atmosphere packaging [9] on fresh-cut pineapple volatiles were assessed. Using an electronic nose, Torri et al. [10] successfully described changes in aroma profiles of cut pineapple flesh stored at different temperatures. However, the influence of harvest maturity and fruit logistics on the composition of volatiles of fresh-cut pineapples has been disregarded in the aforementioned reports.

In the present study, volatiles of fresh-cut pineapple obtained from fully ripe fruit ("air freight") and pineapples harvested at an earlier green-ripe stage that were stored for 14 days prior to processing ("sea freight") were monitored by HS-SPME-GC-MS and multivariate statistical data analysis. In addition, drip loss, $\mathrm{pH}$, total soluble solids (TSS), titratable acidity (TA), carotenoid levels, and microbial quality of the two fresh-cut categories were assessed.

\section{Materials and methods}

\section{Fresh-cut samples}

Green-ripe and fully ripe pineapples (Ananas comosus [L.] Merr. cv. 'MD2' (syn. "Extra Sweet")) were obtained from Jei River Farms (Opeman, Ghana). Green-ripe fruits were harvested $~ 137-145$ days after ethylene induced flower induction (synchronisation) at a TSS of $\sim 9.5-10^{\circ}$ Brix. According to Ghanaian post-harvest procedures for local market and airfreight export, fruits allowed to ripen onplant were harvested $\sim 147-157$ days after synchronisation $\left(\sim 11^{\circ}\right.$ Brix $)$, i.e., $10-12$ days later than those destined for dispatch by sea freight. For "de-greening", green-ripe and fully ripe pineapples were treated with approx. 20 and $10 \mathrm{ppm}$ ethylene, respectively, five days prior to harvest. Pineapples of both categories were harvested by hand and brought to the farm (15 km distance from the field) using a pick-up truck. Subsequently, the pineapples were dispatched to the processing facility (ca. $50 \mathrm{~km})$ using a truck. Prior to processing, green-ripe pineapples were stored at $8{ }^{\circ} \mathrm{C}$ for 14 days, mimicking their sea freight export from West Africa or Central America to Europe. The fully ripe pineapples were processed within $24 \mathrm{~h}$ after harvest.

Flesh cylinders of $83 \times 95 \mathrm{~mm}$ were obtained with a commercial processing machine. Cores were stamped out using a 26-mm bore hollow knife. The fruit flesh was sliced into rings of $1 \mathrm{~cm}$ thickness that were cut into eights. Bits obtained were subsequently dipped into aqueous citric acid solution ( $20 \mathrm{~g} / \mathrm{L})$ and allowed to drip off. Portions of $400 \pm 5 \mathrm{~g}$ were packed into lockable plastic containers $(185 \times 145 \times 55 \mathrm{~mm}$, Safe-t-fresh, Inline Plastics, Shelton, CT, USA). Following packaging, the fresh-cut samples from green-ripe fruit processed after 14 days of storage at $8{ }^{\circ} \mathrm{C}$ and those from fully ripe pineapples were transported to Accra airport and air-freighted to Frankfurt (Germany) lasting approx. 6-7 h. Upon arrival, the samples were dispatched by a forwarding agent to their final destination in Stuttgart. Storage temperature during dispatch and subsequent storage was $8{ }^{\circ} \mathrm{C}$.

Fresh-cut samples were analysed two, five, and eight days after processing (dap). Thus, the relevant shelf life period from the first day of the products' availability on the European market ( 2 dap) to the end of the commercial shelf life (8 dap) was considered. Two packages of each fresh-cut category and storage stage were analysed in analytical duplicates $(n=4)$. 


\section{Reagents}

Sodium chloride was pre-conditioned at $105{ }^{\circ} \mathrm{C}$ for minimum $24 \mathrm{~h}$ prior to use. 2-Methyl-1-pentanol, (all- $E$ )- $\beta$ carotene, (all-E)-violaxanthin, sodium hydroxide, and potassium hydrogen phthalate were purchased from Sigma Aldrich (Taufkirchen, Germany). Purified water was prepared with an ultrapure water system type arium ${ }^{\circledR} 611 \mathrm{UV}$ (Sartorius, Göttingen, Germany) and subsequently boiled for at least $20 \mathrm{~min}$.

\section{Physicochemical characterisation}

The drip loss, i.e., the liquid drained from the pineapple chunks was determined gravimetrically. The $\mathrm{pH}$ and TSS were assessed with an InoLab 720 pH-meter (WTW, Weilheim, Germany) and a Rx-5000 Abbe refractometer (Atago, Tokyo, Japan), respectively. TA expressed as g citric acid per $100 \mathrm{~g}$ of fresh weight (FW) was determined with a Titrino 702 SM (Metrohm, Herisau, Switzerland) titration system [4]. The concentrations of (all-E)- $\beta$-carotene and total carotenoids were determined by HPLC-DAD as detailed elsewhere [11]. Retinol activity equivalents (RAEs) were calculated by converting $12 \mu \mathrm{g}$ dietary (all- $E$ )- $\beta$-carotene to $1 \mu \mathrm{g}$ RAE [12].

\section{Analyses of volatiles}

Volatiles were analysed applying an Agilent GC-MS system type $6890 \mathrm{~N}$ coupled to an Agilent 5975 Mass Selective Detector (both Agilent Technologies, Santa Clara, CA, USA) as reported previously [4]. Briefly, $110 \mathrm{~g}$ pineapple flesh, $10 \mathrm{~mL}$ purified water, and $30 \mathrm{~g}$ sodium chloride were spiked with the internal standard 2-methyl-1-pentanol and homogenised using a laboratory blender. An aliquot of $8.0 \pm 0.1 \mathrm{~g}$ of the puree obtained was filled into a $20-\mathrm{mL}$ headspace vial. Volatiles were isolated from the headspace of the sample tempered to $30^{\circ} \mathrm{C}$ using a polydimethylsiloxane/divinylbenzene fibre (65 $\mu \mathrm{m}$ PDMS/DVB, StableFlex ${ }^{\circledR}$, Supelco 57293-U, Sigma Aldrich) during an incubation time of $60 \mathrm{~min}$.

Volatiles were desorbed for $1 \mathrm{~min}$ in the splitless mode at a temperature of $250{ }^{\circ} \mathrm{C}$. Carrier gas was helium at a constant flow rate of $1.2 \mathrm{~mL} / \mathrm{min}$. GC separation was achieved using a fused silica capillary column coated with a polar polyethylene glycol (PEG) stationary phase $(30 \mathrm{~m} \times 0.25 \mathrm{~mm}$, $d_{\mathrm{f}}=0.25 \mu \mathrm{m}$ DB-Wax, Agilent J\&W Columns, Santa Clara, CA, USA). The temperature program applied was as follows: isothermal hold at $60{ }^{\circ} \mathrm{C}(1 \mathrm{~min})$, constant raise to $170{ }^{\circ} \mathrm{C}$ $\left(3{ }^{\circ} \mathrm{C} / \mathrm{min}\right)$ followed by a ramp to $220^{\circ} \mathrm{C}\left(10^{\circ} \mathrm{C} / \mathrm{min}\right)$ with a final hold time of $10 \mathrm{~min}$. Total run time was $53 \mathrm{~min}$ [4]. For validation of peak identity, the system described above was equipped with a fused silica column coated with a slightly polar 5\% phenyl-containing polydimethylsiloxane stationary phase $\left(30 \mathrm{~m} \times 0.25 \mathrm{~mm}, d_{\mathrm{f}}=0.25 \mu \mathrm{m}\right.$ HP- $5 \mathrm{~ms}$, Agilent $\mathrm{J} \& \mathrm{~W}$ Columns). The following temperature program was applied: isothermal hold at $40{ }^{\circ} \mathrm{C}(1 \mathrm{~min})$, constant raise to $180{ }^{\circ} \mathrm{C}$ $\left(5{ }^{\circ} \mathrm{C} / \mathrm{min}\right)$ followed by a ramp to $250{ }^{\circ} \mathrm{C}\left(10^{\circ} \mathrm{C} / \mathrm{min}\right)$ with a final hold time of $5 \mathrm{~min}$. Total run time was $41 \mathrm{~min}$ [4].

Individual compounds were identified on the basis of their mass spectra compared to Wiley 6N library (Wiley and Sons, NY, USA) and literature data [13, 14]. Linear retention indices (LRI) according to Van den Dool and Kratz [15] were calculated relative to $n$-alkanes. Concentrations of the individual volatiles in $\mu \mathrm{g} / 100 \mathrm{~g}$ were expressed as equivalents of the internal standard 2-methyl-1-pentanol.

\section{Microbiological analyses}

A representative sample of $25 \mathrm{~g}$ of fresh-cut pineapple was taken from a sealed package and blended with $225 \mathrm{~mL}$ of sterile physiological $\mathrm{NaCl}$ solution in a sterile stomacher bag with lateral filter for $120 \mathrm{~s}$ using a Stomacher 400 Circulator (Seward, London, UK). Decimal dilutions of each homogenized sample were prepared in the same diluent and surface spread plated in duplicate on the respective agars. Total aerobic mesophilic plate counts (TPCs) and Pseudomonas spp. viable counts were determined on standard I nutrient (VWR, Darmstadt, Germany) and glutamate starch phenol red (GSP) agar (Merck, Darmstadt, Germany), respectively. Enterobacteriaceae viable counts were assessed using violet red bile dextrose (VRBD) agar (Oxoid, Basingstoke, UK) as previously reported [16]. Yeast and mould plate counts were determined using yeast extract glucose chloramphenicol (YGC) agar (Oxoid). Plates were incubated aerobically at $30{ }^{\circ} \mathrm{C}$ for $48 \mathrm{~h}$ on standard I and GSP agar. Prior to evaluation, samples surface spread on VRBD and YGS agar were incubated at $37{ }^{\circ} \mathrm{C}$ for 24 and $72 \mathrm{~h}$, respectively. Microbial loads were expressed as colony-forming units (CFU) in log scale per gram $\left(\log _{10} \mathrm{CFU} / \mathrm{g}\right)$.

\section{Statistics}

Data obtained by HS-SPME-GC-MS were evaluated by PCA, HCA, and PLS regression calculated using Solo software (release 7.3.1, Eigenvector Research, Wenatchee, WA, USA). The PLS regression biplot was drawn with OriginPro 8 (OriginLab, Northampton, MA, USA) as detailed elsewhere $[4,17]$.

Compounds relevant for class separation in the PCA were calculated by summarising the absolute value of the loadings multiplied with the variance explained by the corresponding principal component [18]. The most discriminative volatiles describing the effect of storage were deduced from the PLS regression using variable identification (VID) coefficients $[17,18]$. 
Significant $(p<0.05)$ differences of means of the physicochemical traits and the microbial loads were determined by analysis of variance (ANOVA) and Tukey's test, applying SAS version 9.4 (SAS Institute, Cary, NC, USA).

\section{Results and discussion}

\section{Physicochemical characterisation}

Physiochemical traits of fresh-cut products from fully ripe air-freighted and green-ripe pineapples after mimicked sea freight are compiled in Table 1. Irrespective of their logistic history, drip loss increased from 5.2-5.4 to 7.2-7.4\% with progressing storage duration of all fresh-cut samples. Both fresh-cut categories displayed comparable TSS of 10.50-10.90 and 10.83-11.10 ${ }^{\circ}$ Brix as determined in the products made from fully and green-ripe pineapples, respectively. By contrast, significantly elevated titratable acids amounting to $0.50-0.53 \mathrm{~g} / 100 \mathrm{~g}$ of FW were determined in the samples from green-ripe fruit (fully ripe: 0.36-0.40 g/100 g of FW). Correspondingly, the TSS/TA, approximating the sugar-to-acid ratios of the fully ripe pineapples ranging between 27.5 and $29.9 \mathrm{~g} / \mathrm{g}$ exceeded those of the sea-freighted samples of merely reaching levels between 21.2 and $22.1 \mathrm{~g} / \mathrm{g}$.

The concentrations of (all- $E$ ) $-\beta$-carotene among all samples amounted to values between 30 and $38 \mu \mathrm{g} / 100 \mathrm{~g}$ of FW. This provitamin A precursor contributed up to $6-10 \%$ of the total carotenoids that ranged between 374 and $518 \mu \mathrm{g} / 100 \mathrm{~g}$ of FW. The total carotenoids tended to decline at the end of the storage experiment ( 8 dap), although not reaching statistical significance $(p<0.05)$. The retinol activity equivalents (RAEs) amounted to 2.5-3.2 $\mu \mathrm{g}$ RAE/100 g of FW, thus being in the range of the 0.3 to $7.3 \mu \mathrm{g} R A E / 100 \mathrm{~g}$ of $\mathrm{FW}$ previously reported in the flesh of 'Sugar Loaf', 'Smooth
Cayenne', 'MD2', and 'Queen Victoria' pineapples from Ghana [11]. In the present study, the impact of harvest maturity and post-processing storage on the (all- $E$ )- $\beta$-carotene and total carotenoid levels of fresh-cut pineapples were found to be insignificant and thus, not further investigated.

\section{HS-SPME-GC-MS profiling analysis}

\section{Assignment of fresh-cut pineapple volatiles}

Table 2 compiles the HS-SPME-GC-MS data of freshcut pineapple volatiles. A total of 131 peaks was detected. Among the tentatively assigned compounds, 91 esters prevailed numerically and quantitatively, comprising 39 and 35 methyl- and ethyl esters, respectively, in addition to 16 acetates as well as 3-methylbutyl hexanoate (64) and ethyl methyl propanedioate (81). Furthermore, 16 terpenes, nine alcohols, six $\gamma$-and $\delta$-lactones, five aldehydes, four undecaene hydrocarbons, and two furanones were tentatively identified. This qualitative composition of volatiles resembled that previously reported for fresh 'MD2' pineapples [4, $5,19]$ and juice obtained thereof [20], except for some juicespecific constituents, such as free fatty acids and diverse norterpenoids, that were not found in the fresh-cut samples assessed herein.

Noteworthy, the concentrations of the volatiles reported in literature as the key odorants of pineapple [21], i.e., ethyl 2-methylpropanoate (no. 8, described to exert a fruity odour), methyl 2-methylbutanoate (11, fruity, apple-like), ethyl 2-methylbutanoate (15, fruity), and 4-hydroxy2,5-dimethyl-3(2H)-furanone (127, sweet, pineapple-like, caramel-like) were found in elevated concentrations in the samples from fully ripe fruit compared to those obtained from green-ripe pineapples stored for 14 days prior to processing. Applying our analytical method, another key aroma compound of pineapples 1-(3E,5Z)-3,5-undecatriene (52b,

Table 1 Physicochemical characteristics of fresh-cut pineapple

\begin{tabular}{|c|c|c|c|c|c|c|}
\hline & $\begin{array}{l}\text { Fully ripe (AF) } \\
2 \text { dap }\end{array}$ & $\begin{array}{l}\text { Fully ripe }(\mathrm{AF}) \\
5 \text { dap }\end{array}$ & $\begin{array}{l}\text { Fully ripe }(\mathrm{AF}) \\
8 \text { dap }\end{array}$ & $\begin{array}{l}\text { Green-ripe (SF) } \\
2 \text { dap }\end{array}$ & $\begin{array}{l}\text { Green-ripe (SF) } \\
5 \text { dap }\end{array}$ & $\begin{array}{l}\text { Green-ripe }(\mathrm{SF}) \\
8 \text { dap }\end{array}$ \\
\hline Drip loss $(\% w / w)$ & $5.4 \pm 1.0 \mathrm{ab}$ & $6.1 \pm 1.0 \mathrm{ab}$ & $7.4 \pm 1.6 \mathrm{a}$ & $5.2 \pm 0.5 b$ & $6.4 \pm 0.2 \mathrm{ab}$ & $7.2 \pm 0.5 \mathrm{ab}$ \\
\hline $\mathrm{pH}(-)$ & $3.75 \pm 0.09 \mathrm{ab}$ & $3.76 \pm 0.09 \mathrm{ab}$ & $3.85 \pm 0.08 \mathrm{a}$ & $3.57 \pm 0.07 b$ & $3.63 \pm 0.09 \mathrm{ab}$ & $3.64 \pm 0.09 b$ \\
\hline TSS $\left({ }^{\circ}\right.$ Brix $)$ & $10.50 \pm 0.87 \mathrm{a}$ & $10.90 \pm 0.81 \mathrm{ab}$ & $10.78 \pm 0.29 a$ & $11.10 \pm 1.94 \mathrm{a}$ & $10.83 \pm 1.91 \mathrm{a}$ & $10.95 \pm 1.80 \mathrm{a}$ \\
\hline TA $(g / 100 \mathrm{~g}$ of $\mathrm{FW})$ & $0.39 \pm 0.04 b$ & $0.40 \pm 0.04 b$ & $0.36 \pm 0.01 b$ & $0.53 \pm 0.02 \mathrm{a}$ & $0.50 \pm 0.05 a$ & $0.52 \pm 0.02 \mathrm{a}$ \\
\hline TSS/TA $(\mathrm{g} / \mathrm{g})$ & $27.9 \pm 2.6 \mathrm{ab}$ & $27.5 \pm 2.8 \mathrm{ab}$ & $29.9 \pm 1.6 \mathrm{a}$ & $21.2 \pm 4.2 \mathrm{~b}$ & $22.1 \pm 4.5 b$ & $21.1 \pm 3.0 \mathrm{~b}$ \\
\hline $\begin{array}{l}\text { (all-E)- } \beta \text {-Carotene }(\mu \mathrm{g} / 100 \mathrm{~g} \text { of } \\
\text { FW) }\end{array}$ & $37 \pm 4 a$ & $33 \pm 5 \mathrm{a}$ & $38 \pm 9 a$ & $34 \pm 5 a$ & $30 \pm 7 \mathrm{a}$ & $34 \pm 5 a$ \\
\hline Total carotenoids ( $\mu \mathrm{g} / 100 \mathrm{~g}$ of FW) & $499 \pm 72 a$ & $518 \pm 72 a$ & $374 \pm 96 a$ & $470 \pm 63 a$ & $484 \pm 24 a$ & $407 \pm 39 a$ \\
\hline RAEs ( $\mu \mathrm{g}$ RAE/100 g of FW) & $3.1 \pm 0.4 \mathrm{a}$ & $2.7 \pm 0.5 \mathrm{a}$ & $3.2 \pm 0.8 \mathrm{a}$ & $2.9 \pm 0.5 \mathrm{a}$ & $2.5 \pm 0.6 \mathrm{a}$ & $2.8 \pm 0.4 \mathrm{a}$ \\
\hline
\end{tabular}

Values represent means \pm standard deviations $(n=4)$

Different letters in one row indicate significant $(p<0.05)$ differences of means 


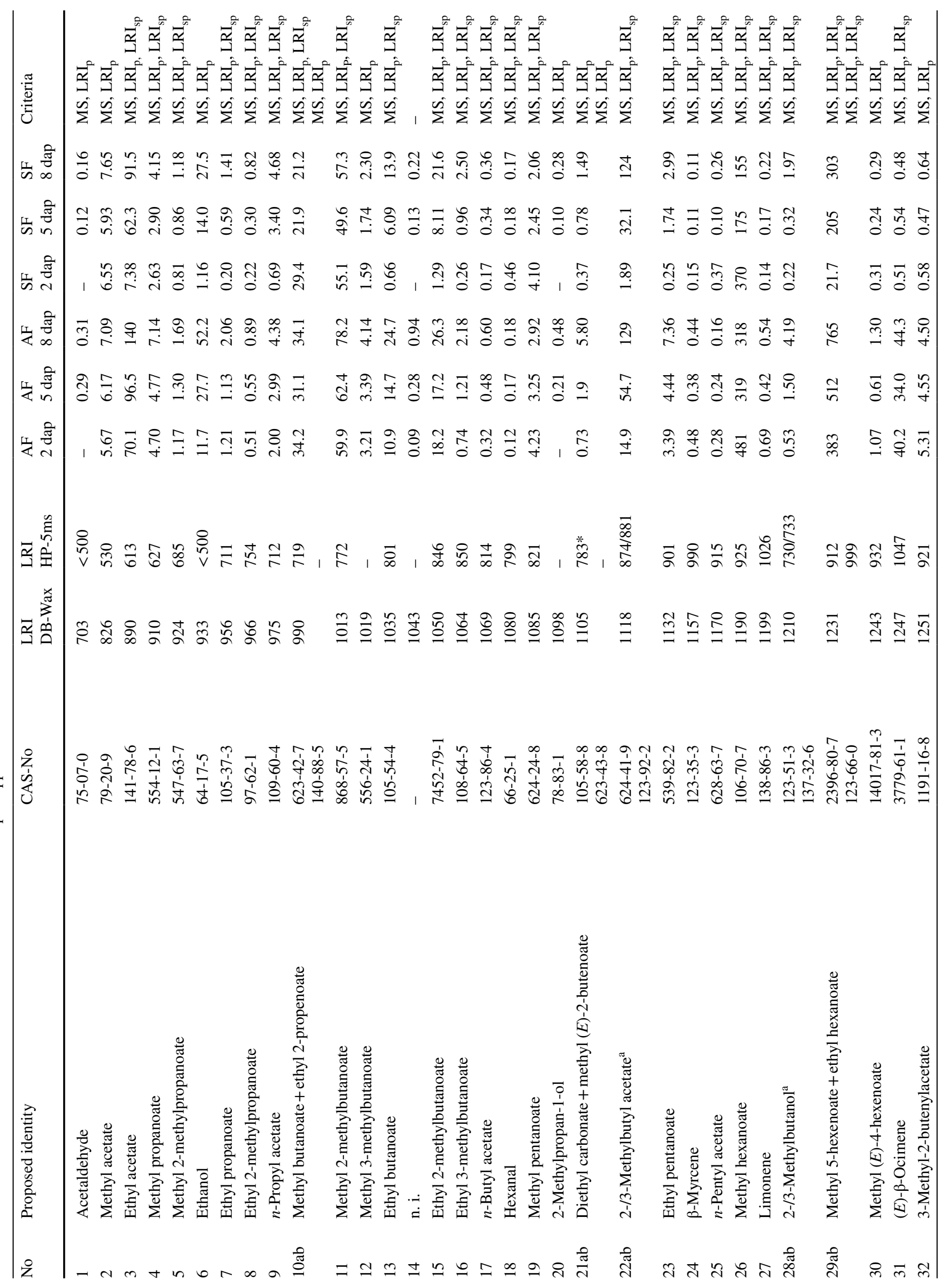




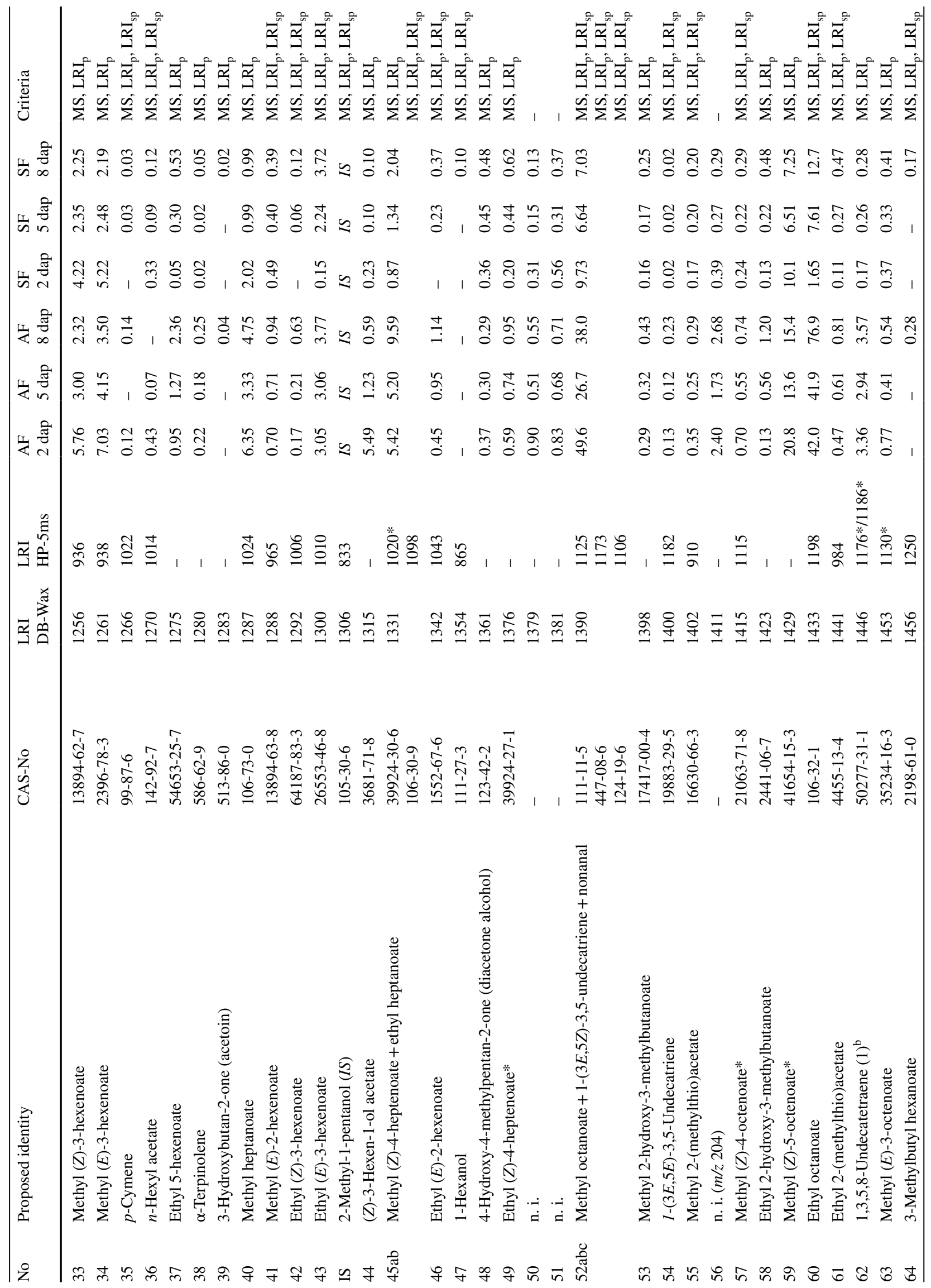




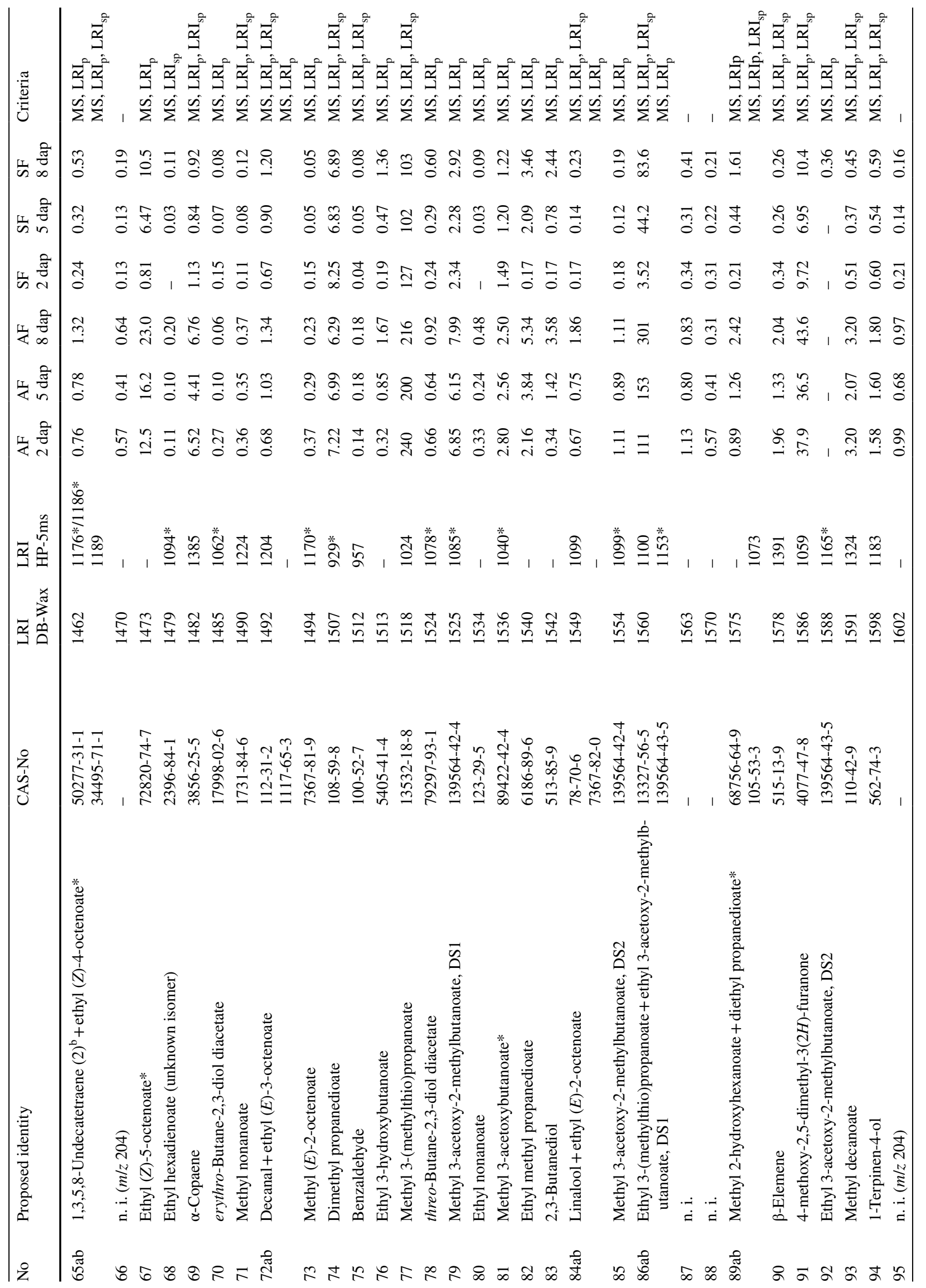




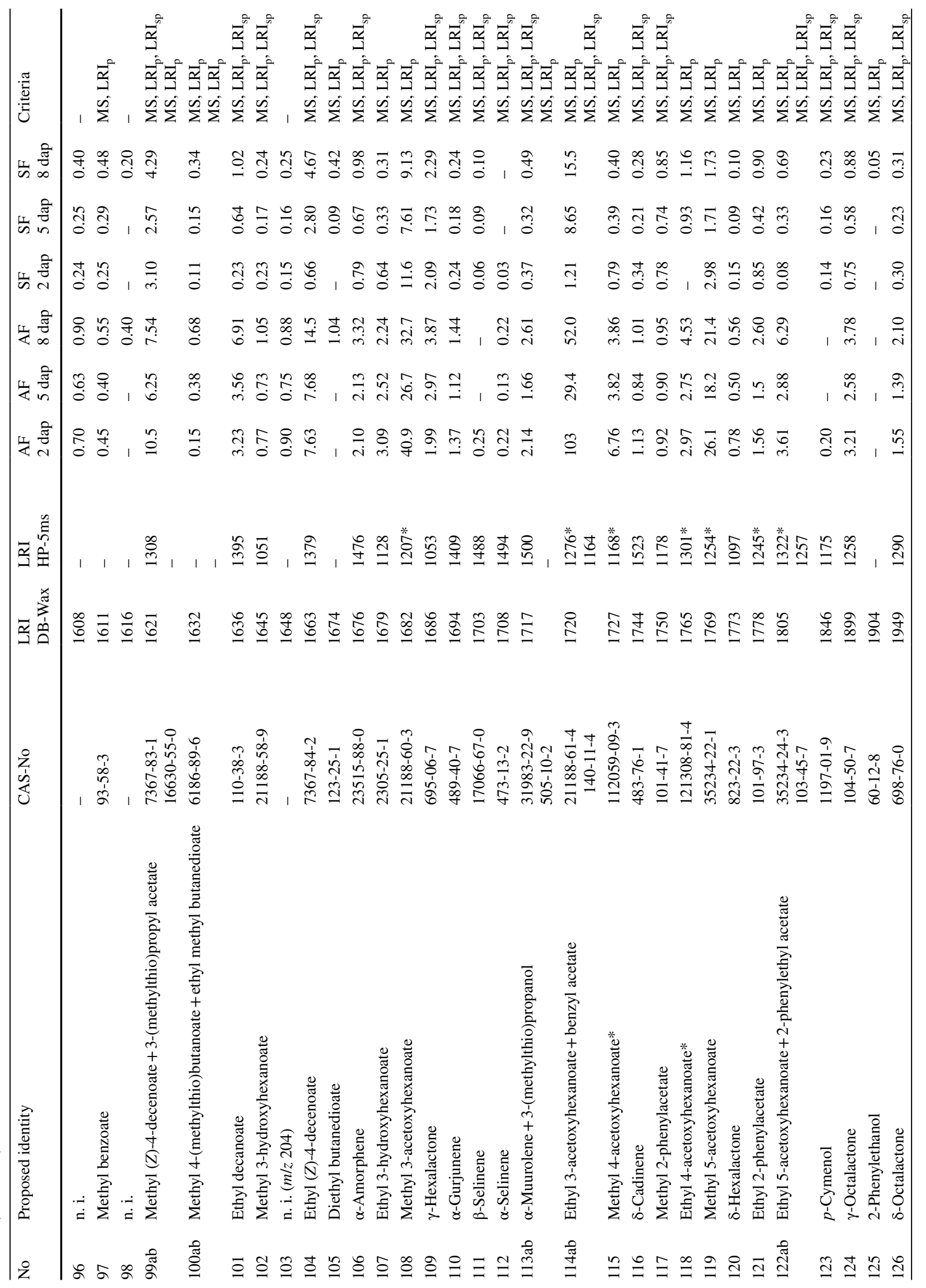




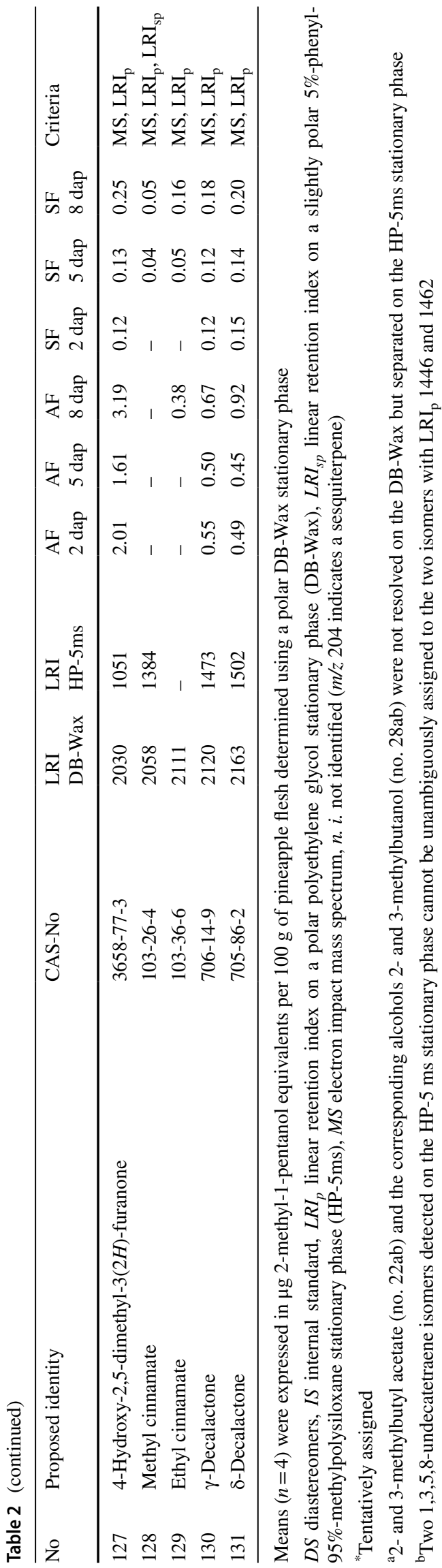

fresh, pineapple-like) was not baseline resolved from the abundant ester methyl octanoate and thus, could not be quantitated separately. Moreover, $\gamma$ - and $\delta$-octalactone (124 and 126 , resp.) that have been proposed to exert the distinct coconut-like odour in fully ripe pineapples [22] were found in elevated concentrations in the AF samples compared to those in the SF fresh-cut produce.

\section{Unsupervised classification by PCA and HCA}

The effect of harvest maturity and post-harvest procedures on fresh-cut pineapple volatiles was assessed by PCA. The scores and correlation loadings obtained for the first two principal components (PCs) are displayed in Fig. 1a, a'. PC1 and $\mathrm{PC} 2$ of the model explained high $80 \%$ of variance. PC1 $(60 \%)$ clearly segregated the fresh-cut samples obtained from green-ripe pineapples after mimicked sea freight (SF) from a second cluster comprising the air-freighted (AF) produce. In addition, the samples were arranged along PC2 (20\%) according to the days after processing. This clustering was also observed in the HCA as illustrated by Fig. 1b and the corresponding circles in the PCA scores plot, respectively.

The most discriminative volatiles contributing to the clustering by PCA are compiled in Table 3. Hereby, volatiles with positive loadings on $\mathrm{PC} 1$ contribute to the differentiation of the two principal fresh-cut categories, i.e., SF and AF produce. In general, elevated concentrations of volatiles were found in the samples from fully ripe fruit compared to those from their sea-freighted counterparts as can be deduced from the arrangement of the loadings on the right part of the plot. Moreover, two sub-groups of volatiles can be distinguished. Whereas those with positive loadings on PC2, i.e., diverse methyl esters of intermediate chain fatty acids (C6-C10), such as methyl 5-acetoxyhexanoate (119), methyl heptanoate (40), methyl octanoate (52a), methyl (Z)-5-octanoate (59), and methyl decanoate (93), were correlated to the freshly processed samples, volatiles with negative loadings on PC2 contributed to the segregation of the stored produce. In particular, ethanol (6) and diverse ethyl esters of short to intermediate chain fatty acids (C2-C7), such as inter alia ethyl acetate (3), ethyl butanoate (13), ethyl pentanoate (23), ethyl hexanoate (29b), and ethyl (Z)4-heptenoate (49), were found among the markers contributing to the clustering of the progressed storage stages. Further discriminative volatiles segregating the latter samples were assigned to ethyl esters, i.e., ethyl 3-hydroxybutanoate (76), ethyl methyl propanedioate (82) and the sulphurous volatile ethyl 3-(methylthio)propanoate (86a). The latter was not baseline resolved from the unique pineapple constituent ethyl 3-acetoxy-2-methylbutanoate (86b) [13] on a PEG stationary phase. 

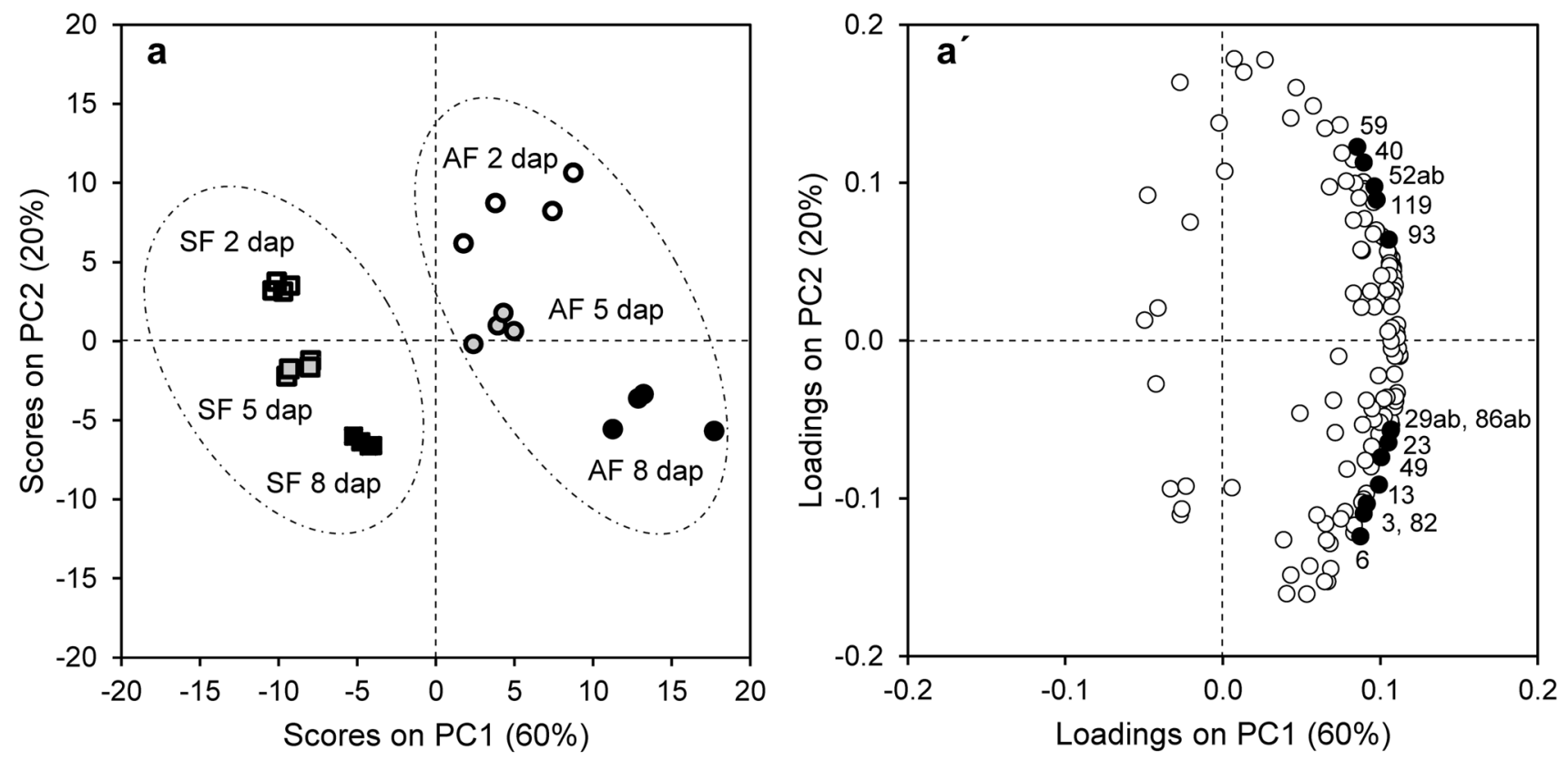

b

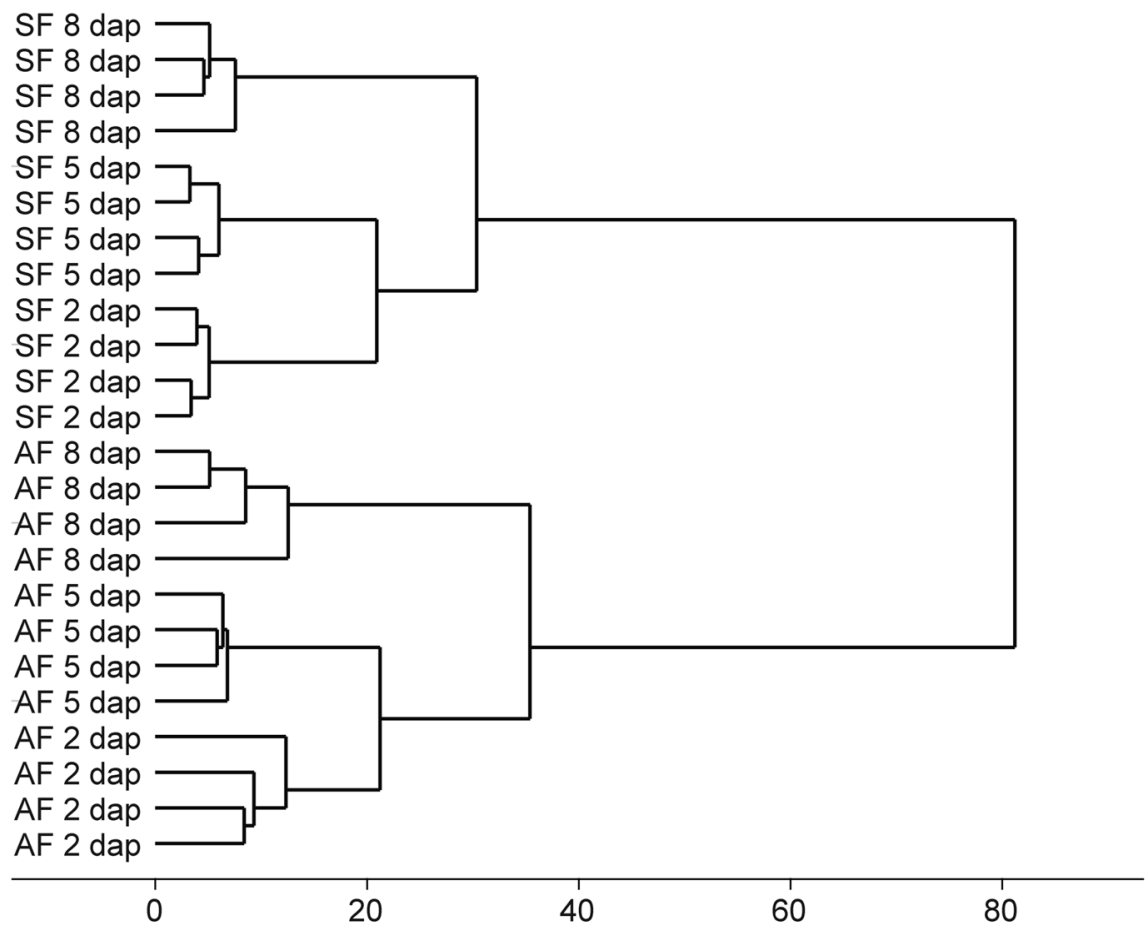

Variance Weighted Distance Between Cluster Centers

Fig. 1 PCA scores (a) and loadings plot (a') illustrating the effect of harvest maturity and storage duration on fresh-cut pineapple volatiles. The large circles represent the clusters obtained by HCA (b). dap days after processing, $A F$ fresh-cut samples from fruit harvested at

In summary, methyl esters prevailed in the fresh samples, whereas diverse ethyl esters were generated with progressing storage duration. This shift from methyl to ethyl esters has been previously observed during post-harvest storage of a full maturity ("air freight"), $S F$ fresh-cut produce from green-ripe fruit stored for 14 days prior to processing ("sea freight"). Loadings of tentative markers are highlighted by filled circles and labelled with the compound numbers compiled in Table 3

pineapple fruit and may be triggered by the endogenous and possibly microbial genesis of ethanol [4]. Noteworthy, the differences in the volatiles between fully ripe fruit and those harvested at a green-ripe stage following chilled storage for 
Table 3 Tentative marker compounds identified via PCA

\begin{tabular}{llll}
\hline No. & Identity & PC 1 (60\%) & PC 2 (20\%) \\
\hline 13 & Ethyl butanoate & 0.099 & -0.091 \\
$52 \mathrm{abc}$ & Methyl octanoate +1-(3E,5Z)-3,5-undecatriene + nonanal & 0.096 & 0.098 \\
6 & Ethanol & 0.087 & -0.124 \\
119 & Methyl 5-acetoxyhexanoate & 0.098 & 0.089 \\
40 & Methyl heptanoate & 0.089 & 0.113 \\
59 & Methyl (Z)-5-octenoate & 0.085 & 0.123 \\
93 & Methyl decanoate & 0.105 & 0.064 \\
23 & Ethyl pentanoate & 0.105 & -0.064 \\
82 & Ethyl methyl propanedioate & 0.089 & -0.109 \\
3 & Ethyl acetate & 0.092 & -0.103 \\
$29 \mathrm{ab}$ & Methyl 5-hexenoate + ethyl hexanoate & 0.107 & -0.057 \\
$86 \mathrm{ab}$ & Ethyl 3-(methylthio)propanoate + ethyl 3-acetoxy-2-methylb- & 0.107 & -0.056 \\
& $\quad$ utanoate, DS1 & & -0.074 \\
49 & Ethyl (Z)-4-heptenoate & 0.101 &
\end{tabular}

$D S$ diastereomer

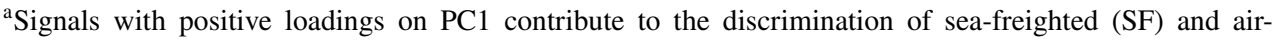
freighted samples (see Fig. 1a, a')

${ }^{b}$ Signals with positive loadings on PC2 are correlated to the fresh samples, those with negative to the stored produce (see Fig. 1a, a')
14 days were largely retained throughout the entire storage period. To further explore the particular effect of postprocessing storage, a PLS regression was calculated as discussed in the following section.

\section{PLS regression}

The scores and correlation loadings obtained for the first two latent variables (LVs) of the PLS regression model are illustrated in Fig. 2. As also observed in the PCA, the samples are arranged in two clusters comprising the air-freighted products and those obtained from green-ripe pineapples after mimicked sea freight. In addition, the model clearly fitted an effect of storage as indicated by the high $98 \%$ of cumulative variance in the $y$-variable explained by LV1 $(Y=79 \%)$ and LV2 $(Y=19 \%)$, as well as by the length of the correlation loadings vector.

Variable identification (VID) coefficients revealed distinctive volatiles (Table 4). Hereby, positive VIDs indicate the genesis of the respective compound with progressing storage duration. In most instances, such volatiles were alcohols deriving from fermentative metabolic pathways, i.e., ethanol (6), 2-methylpropanol (20), 2-/3-methylbutanol (28ab), and 2,3-butanediol (83). Moreover, the acetates $n$-propyl acetate (9) and 2-/3-methylbutyl acetate (22ab) in addition to diverse ethyl esters, e.g., ethyl 3-methylbutanoate (16), ethyl 2-hydroxy-3-methylbutanoate (58), and diethyl butanedioate (105) were found as possible markers generated with progressing storage. Vice versa, the concentrations of the volatiles with negative VIDs, here methyl pentanoate (19), methyl (Z)-3-hexenoate (33), and $n$-hexyl acetate (36)

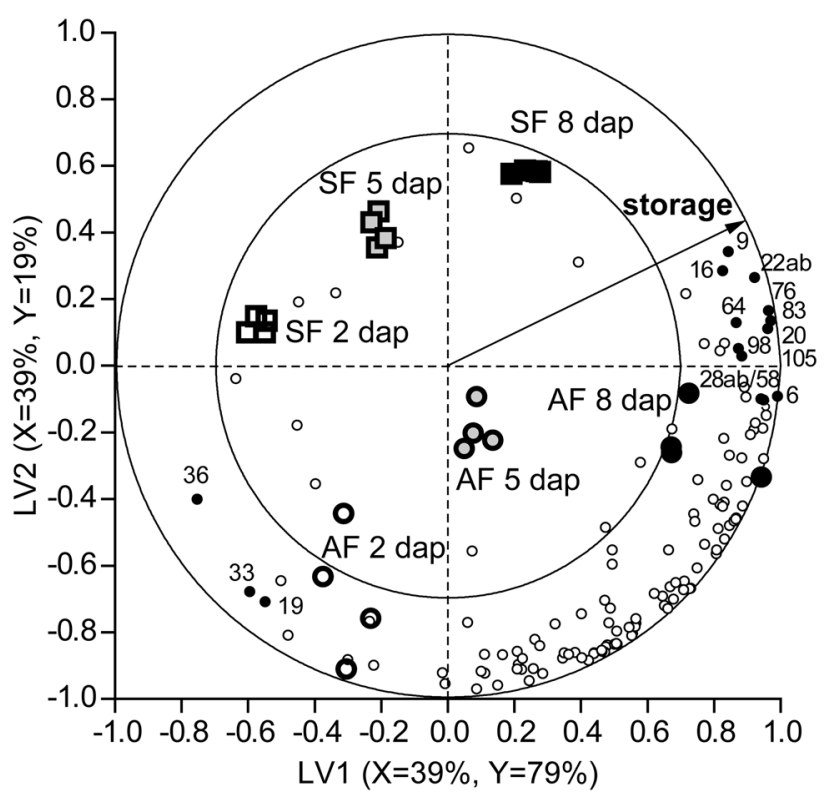

Fig. 2 PLS regression illustrating the effect of storage on fresh-cut pineapple volatiles. Volatiles with $\mathrm{VID} \geq \mid 0.80 \mathrm{l}$ are displayed as filled circles and labelled with the peak numbers compiled in Table 4

decreased during storage. This may be attributed to transesterification reactions or possibly the enzymatic cleavage of certain esters during storage of fresh-cut pineapples as previously described by Lamikanra [7]. Interestingly, 2,3-butanediol (83) that was found as a putative storage marker of fresh-cut produce represents a precursor of threo- and erythro-2,3-butanediol diacetate that have been reported to arise during post-harvest storage of green-ripe pineapples [4, 
Table 4 Discriminative volatiles (VID $\geq|0.80|$ ) indicating the effect of storage on fresh-cut pineapples identified via PLS regression

\begin{tabular}{llr}
\hline No. & Identity & $\mathrm{VID}^{\mathrm{a}}$ \\
\hline 22ab & 2-/3-Methylbutyl acetate & 0.94 \\
76 & Ethyl 3-hydroxybutanoate & 0.94 \\
83 & 2,3-Butanediol & 0.93 \\
20 & 2-Methylpropan-1-ol & 0.91 \\
9 & n-Propyl acetate & 0.91 \\
16 & Ethyl 3-methylbutanoate & 0.87 \\
6 & Ethanol & 0.85 \\
64 & 3-Methylbutyl hexanoate & 0.84 \\
58 & Ethyl 2-hydroxy-3-methylbutanoate & 0.81 \\
98 & n. i. & 0.81 \\
105 & Diethyl butanedioate & 0.81 \\
$28 \mathrm{ab}$ & 2-/3-Methylbutanol & 0.80 \\
19 & Methyl pentanoate & -0.81 \\
33 & Methyl (Z)-3-hexenoate & -0.83 \\
36 & $n$-Hexyl acetate & -0.85 \\
\hline
\end{tabular}

n. $i$. not identified

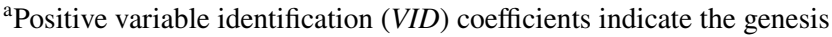
of the volatiles. Vice versa, negative VID coefficients indicate diminishing concentrations with progressing storage duration (see also Fig. 2 and concentrations compiled in Table 2)

13]. Most of the aforementioned volatiles may derive from endogenous metabolic pathways, but also from microbial growth that was assessed in the second part of this study.

\section{Microbiological analysis}

To further characterise the influence of post-harvest procedures on the quality of fresh-cut pineapples, total plate counts (TPCs), pseudomonads, Enterobacteriaceae, and the yeast and mould counts were assessed. Enterobacteriaceae were not detected across all samples (not shown in Fig. 3).

With progressing storage duration, the TPCs increased in both fresh-cut categories (Fig. 3a). However, the TPCs determined in the air-freighted products (AF 3.3-4.4 $\log _{10}$ $\mathrm{CFU} / \mathrm{g}$ ) were significantly smaller than those in their counterparts obtained from pineapples after mimicked sea freight (SF 4.6-6.5 $\log _{10}$ CFU/g). Compared to the TPCs, Pseudomonas spp. viable counts were found at lower levels of 3.2-3.5 $\log _{10}$ CFU/g (AF) and 3.2-4.1 $\log _{10} \mathrm{CFU} / \mathrm{g}(\mathrm{SF})$ as determined across all air- and sea-freighted samples, respectively. In both sample categories, the pseudomonads only slightly increased during storage (Fig. 3b).

Whereas the initial TPC already differed comparing the $\mathrm{AF}$ and SF samples, comparable yeast and mould counts of 3.4 and $3.6 \log _{10} \mathrm{CFU} / \mathrm{g}$, respectively, were found in the two fresh-cut categories assessed 2 dap (Fig. 3c). However, with progressing storage, the yeasts and moulds significantly increased and the plate counts of the sea-freighted samples air freight $(\mathrm{AF}) \quad$ sea freight $(\mathrm{SF})$
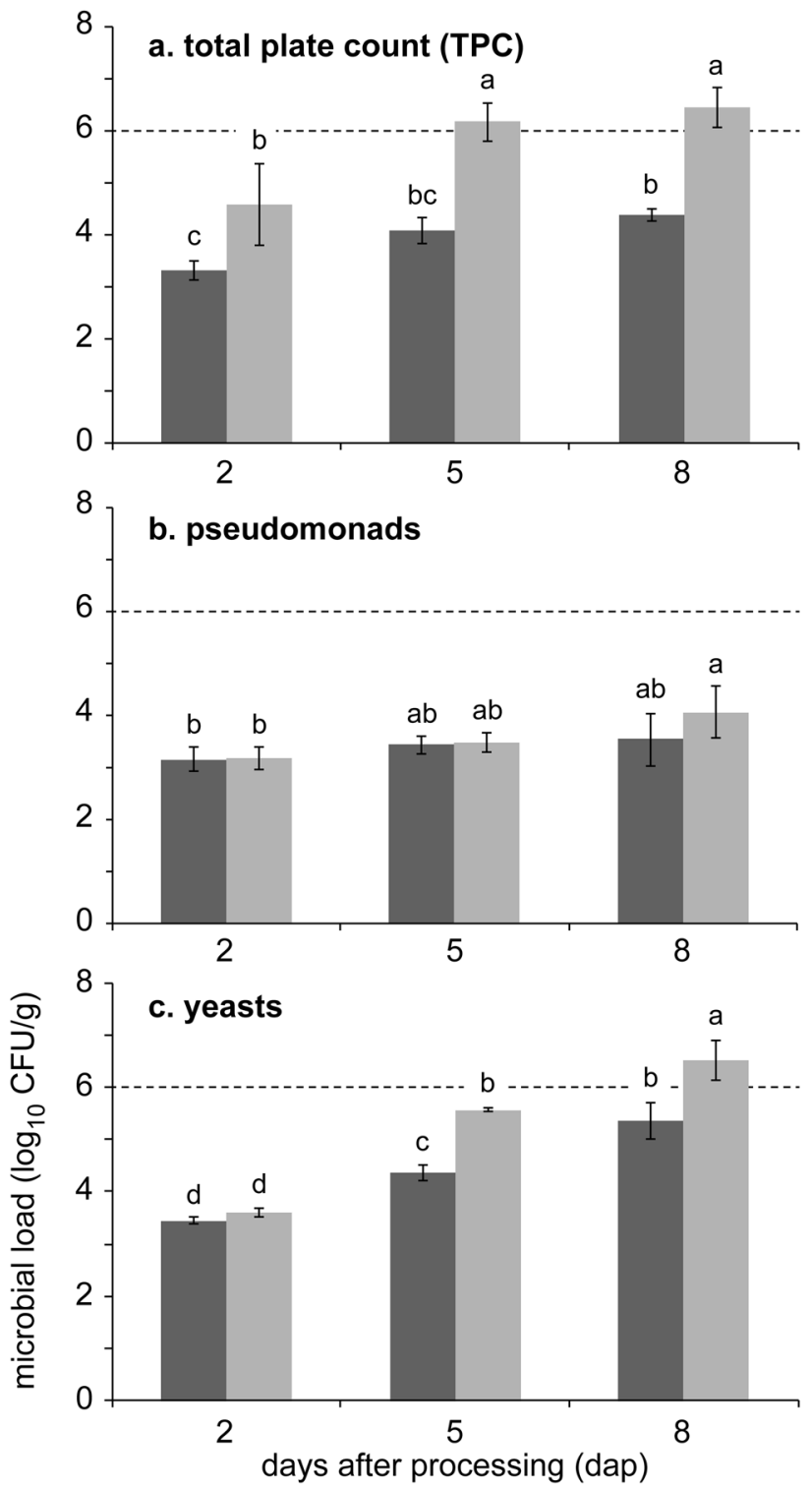

Fig. 3 Total plate count, TPCs (a), pseudomonads (b), and yeast and mould counts (c) in fresh-cut pineapples displayed as $\log _{10} \mathrm{CFU} / \mathrm{g}$. Enterobacteriaceae were not detected among all samples assessed (data not shown). Different letters indicate significant $(p<0.05)$ differences of means. The dashed line indicates the maximum acceptable plate count for fresh-cut fruit of $6.0 \log _{10} \mathrm{CFU}$ as specified by the IFST [23]

(SF 5.6 and $6.5 \log _{10}$ CFU/g as determined 5 and 8 dap, respectively) clearly exceeded those of the air-freighted produce (AF 4.4 and $5.4 \log _{10}$ CFU/g, resp.).

Yeasts and moulds have been reported to be the most important spoilage microorganisms of fresh-cut fruits [23]. According to the Institute of Food Science and Technology (IFST) [23], the maximum acceptable plate count of $6.0 \log _{10} \mathrm{CFU} / \mathrm{g}$ shall not be exceeded during the entire shelf 
life of sliced fruits stored under chilled conditions. All AF samples assessed displayed microbial loads smaller than $6.0 \log _{10} \mathrm{CFU} / \mathrm{g}$, whereas the TPC as well as the yeast and mould count determined in the SF pineapples exceeded this critical value already five and eight days after processing, respectively (see dashed line in Fig. 3). Noteworthy, the pineapple flesh is not sterile and contains fungi, yeasts, and bacteria [24]. Storage of the green-ripe pineapples prior to processing may result in the elevated TPCs observed in the SF samples, possibly from the growth of this genuine microflora. Concluding, processing freshly harvested pineapples at full maturity resulted in lower total plate as well as yeast and mould counts compared to samples from the green-ripe fruit that were stored for 14 days prior to processing.

\section{Conclusion}

With the exception of the drip loss, the titratable acids, and the TSS/TA ratio, post-harvest procedures had only a marginal impact on the physicochemical properties of freshcut pineapples. By contrast, processing fully ripe pineapples resulted in lower total plate as well as yeast and mould counts compared to samples from green-ripe fruit stored for 14 days prior to processing. Consequently, processing fully ripe pineapples immediately after harvest may be recommended for fresh-cut processors targeting the premium market rather than using sea-freighted fruit. Moreover, HSSPME-GC-MS analysis of volatiles allowed the unambiguous distinction between fresh-cut products obtained from fruit harvested at full maturity and green-ripe pineapples stored for 14 days mimicking their sea freight export.

In most instances, elevated concentrations of volatiles were found among the products from fully ripe pineapples. With progressing storage duration, additional volatiles deriving from fermentative metabolic pathways, i.e., diverse alcohols and ethyl esters, were generated.

Concluding, in particular the factors determining the sensory properties, i.e., TSS/TA and the aroma-determining volatiles were the most distinctive traits to discriminate airfreighted fresh-cut pineapples from the produce obtained from sea-freighted fruit. Hence, air-freighted fresh-cut produce may be recommended for consumers that desire to experience the unique aroma quality of fully ripe pineapples. The differing composition of volatiles indicates distinct sensory properties of the two fresh-cut categories assessed that may be subject of ongoing research.

Acknowledgements We gratefully thank Frank Oberschilp (Peelco Ltd., Accra, Ghana) and Fritz Schumacher (Schumacher GmbH, Filderstadt-Bernhausen, Germany) for donating the samples and organisation of the export trial.
Funding Open Access funding enabled and organized by Projekt DEAL.

\section{Declarations}

Conflict of interest The authors declare no conflict of interest.

Compliance with ethics requirements This article does not contain any studies with human or animal subjects.

Open Access This article is licensed under a Creative Commons Attribution 4.0 International License, which permits use, sharing, adaptation, distribution and reproduction in any medium or format, as long as you give appropriate credit to the original author(s) and the source, provide a link to the Creative Commons licence, and indicate if changes were made. The images or other third party material in this article are included in the article's Creative Commons licence, unless indicated otherwise in a credit line to the material. If material is not included in the article's Creative Commons licence and your intended use is not permitted by statutory regulation or exceeds the permitted use, you will need to obtain permission directly from the copyright holder. To view a copy of this licence, visit http://creativecommons.org/licenses/by/4.0/.

\section{References}

1. Rohrbach KG, Leal F, Coppens d'Eeckenbrugge G, (2003) History, distribution and world production. In: Bartholomew DP, Paull RE, Rohrbach KG (eds) The pineapple: botany, production and uses. CABI Publishing, Wallingford, pp 1-32

2. Jaeger P (2008) Ghana export horticulture cluster strategic profile study: part I-scoping review. http://www.euacpcommodities.eu/. Accessed 06 Aug 2013

3. Montero-Calderón M, Rojas-Graü MA, Martín-Belloso O (2010) Pineapple (Ananas comosus [L.] Merril) flavor. In: Hui YH (ed) Handbook of fruit and vegetable flavors. Wiley, Hoboken, pp 391-414

4. Steingass CB, Grauwet T, Carle R (2014) Influence of harvest maturity and fruit logistics on pineapple (Ananas comosus [L.] Merr.) volatiles assessed by headspace solid phase microextraction and gas chromatography-mass spectrometry (HS-SPME-GC/ MS). Food Chem 150:382-391. https://doi.org/10.1016/j.foodc hem.2013.10.092

5. Steingass CB, Dell C, Lieb V et al (2016) Assignment of distinctive volatiles, descriptive sensory analysis and consumer preference of differently ripened and post-harvest handled pineapple (Ananas comosus [L.] Merr.) fruits. Eur Food Res Technol 242:33-43. https://doi.org/10.1007/s00217-015-2515-x

6. Spanier AM, Flores M, James C et al (1998) Fresh-cut pineapple (Ananas sp.) flavor. Effect of storage. In: Contis ET, Ho C-T, Mussinan CJ et al (eds) Food flavors: formation, analysis and packaging influences: proceedings of the 9th international flavor conference. The George Charalambous memorial symposium, vol 40. Elsevier, Amsterdam, pp 331-343

7. Lamikanra $\mathrm{O}$ (2003) The role of esterified compounds in the development of staleness in fresh-cut fruits. In: Hofmann T, Ho CT, Pickenhagen W (eds) Challenges in taste chemistry and biology, vol 867. American Chemical Society, Washington, pp 263-274

8. Lamikanra O, Richard OA (2004) Storage and ultraviolet-induced tissue stress effects on fresh-cut pineapple. J Sci Food Agric 84:1812-1816. https://doi.org/10.1002/jsfa.1891 
9. Montero-Calderón M, Rojas-Graü MA, Aguiló-Aguayo I et al (2010) Influence of modified atmosphere packaging on volatile compounds and physicochemical and antioxidant attributes of fresh-cut pineapple (Ananas comosus). J Agric Food Chem 58:5042-5049. https://doi.org/10.1021/jf904585h

10. Torri L, Sinelli N, Limbo S (2010) Shelf life evaluation of freshcut pineapple by using an electronic nose. Postharvest Biol Technol 56:239-245. https://doi.org/10.1016/j.postharvbio.2010.01. 012

11. Steingass CB, Vollmer K, Lux PE et al (2020) HPLC-DADAPCI-MSn analysis of the genuine carotenoid pattern of pineapple (Ananas comosus [L.] Merr.) infructescence. Food Res Int. https://doi.org/10.1016/j.foodres.2019.108709

12. U.S. Institute of Medicine (2010) Dietary reference intakes for vitamin $\mathrm{A}$, vitamin $\mathrm{K}$, arsenic, boron, chromium, copper, iodine, iron, manganese, molybdenum, nickel, silicon, vanadium, and zinc: a report of the Panel on Micronutrients ... and the Standing Committee on the Scientific Evaluation of Dietary Reference Intakes, Food and Nutrition Board. National Academy Press, Institute of Medicine Washington, D.C

13. Umano K, Hagi Y, Nakahara K et al (1992) Volatile constituents of green and ripened pineapple (Ananas comosus [L.] Merr.). J Agric Food Chem 40:599-603. https://doi.org/10.1021/jf000 $16 \mathrm{a} 014$

14. Takeoka G, Buttery RG, Flath RA et al (1989) Volatile constituents of pineapple Ananas comosus [L.] Merr. In: Teranishi R, Buttery RG, Shahidi F (eds) Flavor chemistry: trends and developments, vol 388. American Chemical Society, Washington, pp 223-237

15. Van den Dool H, Kratz PD (1963) A generalization of the retention index system including linear temperature programmed gasliquid partition chromatography. J Chromatogr A 11:463-471. https://doi.org/10.1016/S0021-9673(01)80947-X

16. Wulfkuehler S, Dietz J, Schmidt H et al (2014) Quality of freshcut radicchio cv. Rosso di Chioggia (Cichorium intybus L. var. foliosum Hegi) as affected by water jet cutting and different washing procedures. Eur Food Res Technol 240:159-172. https://doi. org/10.1007/s00217-014-2317-6

17. Vervoort L, Grauwet T, Kebede BT et al (2012) Headspace fingerprinting as an untargeted approach to compare novel and traditional processing technologies: a case-study on orange juice pasteurisation. Food Chem 134:2303-2312. https://doi.org/10. 1016/j.foodchem.2012.03.096

18. Steingass CB, Jutzi M, Müller J et al (2015) Ripening-dependent metabolic changes in the volatiles of pineapple (Ananas comosus (L.) Merr.) fruit: II. Multivariate statistical profiling of pineapple aroma compounds based on comprehensive two-dimensional gas chromatography-mass spectrometry. Anal Bioanal Chem 407:2609-2624. https://doi.org/10.1007/s00216-015-8475-y

19. Steingass CB, Carle R, Schmarr H-G (2015) Ripening-dependent metabolic changes in the volatiles of pineapple (Ananas comosus (L.) Merr.) fruit: I. Characterization of pineapple aroma compounds by comprehensive two-dimensional gas chromatographymass spectrometry. Anal Bioanal Chem 407:2591-2608. https:// doi.org/10.1007/s00216-015-8474-z

20. Vollmer K, Czerny M, Vásquez-Caicedo AL et al (2021) Nonthermal processing of pineapple (Ananas comosus L. Merr.) juice using continuous pressure change technology (PCT): HS-SPMEGC-MS profiling, descriptive sensory analysis, and consumer acceptance. Food Chem 345:128786. https://doi.org/10.1016/j. foodchem.2020.128786

21. Tokitomo Y, Steinhaus M, Büttner A et al (2005) Odor-active constituents in fresh pineapple (Ananas comosus [L.] Merr.) by quantitative and sensory evaluation. Biosci Biotechnol Biochem 69:1323-1330. https://doi.org/10.1271/bbb.69.1323

22. Flath RA (1980) Pineapple. In: Nagy S, Shaw PE (eds) Tropical and subtropical fruits: composition, properties and uses. AVI Publishing Company, Westport, pp 157-183

23. Stannard C (1997) Development and use of microbiological criteria for foods. Food Sci Technol Today 11:137-177

24. Rohrbach KG, Apt WJ (1986) Nematode and disease problems of pineapple. Plant Dis 70:81-87

Publisher's Note Springer Nature remains neutral with regard to jurisdictional claims in published maps and institutional affiliations. 